\title{
Sobre mulheres fortes e homens ausentes? Pensando conjugalidades como processos em Cabo Verde
}

\author{
Andréa Lobo \\ Professora do Departamento de Antropologia da Universidade de Brasília \\ Professora visitante na Université Catholique de Louvain, Bélgica \\ andreaslobo@yahoo.com.br
}

\begin{abstract}
Resumo $\mathrm{O}$ artigo aborda as afetividades, as formas possíveis de conjugalidades e os dilemas enfrentados por homens e mulheres, mas, sobretudo, por mulheres, no processo de construção de relações conjugais. Os dados de pesquisa têm como lócus o arquipélago de Cabo Verde, especialmente a Ilha da Boa Vista. Em Cabo Verde, as relações familiares seriam marcadas por uma centralidade feminina combinada com um sistema patriarcal. O laço afetivo fundamental nesse contexto seria aquele estabelecido entre mãe e filho(a), e as relações de filiação teriam preponderância sobre aquelas baseadas na afinidade. Argumento nesta pesquisa que as relações afetivo-conjugais são vividas de formas distintas nos percursos de vida de homens e mulheres e têm reflexos sobre os ciclos de vida dos grupos domésticos. Destaco ainda as formas que a conjugalidade pode assumir ao longo da vida e as estratégias de construção de proximidades adotadas pelas mulheres no cotidiano de suas relações com os homens.
\end{abstract}

Palavras-chave: conjugalidades, afetividades, ciclos de vida, Cabo Verde, famílias.

$\mathrm{O}$ tema do presente artigo é a afetividade, as formas possíveis de conjugalidades e os dilemas enfrentados pelos homens e, principalmente, pelas mulheres do arquipélago de Cabo Verde no processo de construção de relações conjugais, em especial, na Ilha da Boa Vista. ${ }^{1}$ As análises sobre esta temática ${ }^{2}$ indicam que, em Cabo Verde, as relações familiares seriam marcadas por uma centralidade feminina combinada com um sistema patriarcal. O laço afetivo fundamental seria o laço existente entre mãe e filho(a). Como consequência, as relações de filiação teriam preponderância sobre aquelas baseadas na afinidade, sendo o laço entre o casal mais frouxo e mais tênue e os de filiação mais sólidos e duradouros. Paradoxalmente, tal dinâmica seria vivida em um contexto de valorização do modelo de construção de um lar nuclear, patriarcal e monogâmico, no qual a presença física, financeira e afetiva do marido-pai teria um valor central. A relativa discrepância entre a realidade das práticas familiares, atualizadas em especial nas classes populares, e o almejar de um tipo de configuração familiar que nunca se realiza seria explicada pelo processo de formação desta sociedade criou-

1 O texto é resultado do retorno aos dados de uma pesquisa realizada em meados dos anos 2000, na qual analiso a organização familiar na llha da Boa Vista. Trata-se de uma versão amadurecida pela mediação do tempo, após dez anos do trabalho de campo e da escrita da primeira versão do material analítico.

2 Ver Fortes (2013, 2015), Barros (2013), Drotbohm (2009), Correia e Silva (2014), Lobo (2006, 2012a, 2012b, 2014), Defrayne (2016) e Laurent (2016). 
la, que teria como referenciais os modelos europeu e africano sempre em relação e disputa. ${ }^{3}$

Apesar de partilhar, parcialmente, do caminho analítico seguido pelos que estudam a temática, creio ser interessante ponderar, também, a partir dos casos que retomo aqui, sobre o suposto dilema entre o devir e a realidade no universo afetivo cabo-verdiano. Trata-se de uma disputa entre modelos de conjugalidade ou desta sendo vivida como um processo que assume formas distintas ao longo dos ciclos de vida de mulheres, homens e casais?

Inspiro-me no diálogo que Janet Carsten (2000) realiza com Meyer Fortes (1974) ao recuperar algumas de suas ideias. Em sua reflexão sobre o ciclo de desenvolvimento do grupo doméstico, Carsten introduz o fator tempo no entendimento da estrutura social, ou seja, o sistema social passa a ter vida, sendo percebido como dinâmico. Tomando como exemplo os tipos de residência, que vieram a ser caracterizados com tipologias específicas nos estudos de parentesco, M. Fortes afirma que a não consideração do desenvolvimento das organizações domésticas poderia causar sérias distorções na interpretação dos fatos: haveria o risco de se definir como um tipo ou padrão de residência aquilo que, na verdade, era apenas um momento dentro de um ciclo maior. Em outras palavras, em sociedades cujo padrão de residência era considerado uxorilocal, por exemplo, o que poderia existir, de fato, em vez desse padrão, eram tipos diferenciados de moradia a depender da fase em que os indivíduos se encontrassem (Fortes, 1974).

Com M. Fortes já se percebe que as dinâmicas familiares só se tornam visíveis quando, na tentativa de vislumbrar a lógica de um sistema mais amplo de relações sociais, a análise vai além da unidade doméstica isolada e do momento presente. O que ele realiza no contexto dos estudos de parentesco da época é um deslocamento das categorias (parentesco, aliança e descendência) para uma visão mais processual. Como lembra Carsten (2000), Fortes ainda dá pouca ou nenhuma atenção à intimidade dos arranjos domésticos e aos comportamentos e afetividades ligados a eles, mas sua visão processual se apresenta como um avanço nos debates da época.

Mais recentemente, em especial após a "virada feminista" que fez ressurgir os estudos sobre família e parentesco, cuja morte havia sido decretada por Schneider (1984), tem sido uma perspectiva fecunda e atrativa olhar para as relações entre parentes como algo que pode formar-se, dispersar-se e desenvolver-se pelas experiências cotidianas. Esta, aliás, é a perspectiva da qual me aproximo na presente análise. Certamente, as questões que me mobilizam têm como origem a percepção de que as relações fami- liares são construídas em uma arena de negociação e de alguma flexibilidade; entretanto, concordo com Miller (2007) quando este nos lembra que relações são compostas, também, por normatividade, formalização e fixidez - e estas esferas não devem desaparecer de nosso olhar analítico.

Portanto, tendo como pano de fundo este debate teórico e, como base, os relatos de mulheres em idade madura que constroem suas trajetórias familiares por meio da memória e ainda as reflexões de jovens que, durante meu trabalho de campo, viviam relações afetivo-conjugais marcadas pelos dilemas em questão, revisito minhas próprias análises (Lobo, 2006, 2012a, 2012b, 2014) e as de outros autores (Fortes, 2013, 2015; Barros, 2013; Drotbohm, 2009; Correia; Silva, 2014; Laurent, 2016). Defendo que a ideia de processo no estudo da temática presente oferece um potencial analítico para entender as dinâmicas afetivo-conjugais no arquipélago não enquanto um tipo alternativo a um modelo hegemônico que, ao fim e ao cabo, é almejado e não realizado; tais dinâmicas devem constituir um processo que assume configurações diversas ao longo do ciclo de vida de pessoas e grupos familiares.

\section{Sobre (des)estruturas}

O arquipélago de Cabo Verde situa-se na costa ocidental africana. Trata-se de um pequeno país insular composto de dez ilhas (nove habitadas) que abrigam uma população de cerca de quinhentos mil habitantes. A moderna sociedade crioula de Cabo Verde é resultado do achamento das ilhas desabitadas por Portugal e sua posterior colonização. O povoamento das ilhas se efetiva no contexto do tráfico negreiro, formando-se uma sociedade escravocrata e mercantil. A sociedade crioula nasce de contatos intensos, profundos e duradouros, marcados pela desigualdade de poder entre uma classe dominante de colonizadores europeus e uma classe dominada composta por povos africanos oriundos de vários países do continente. Ela é fruto de contatos com profundas interpenetrações, no seio dos quais tanto dominadores quanto dominados sofrem influências recíprocas e adaptações a condições sociais, geográficas e ambientais novas (Trajano Filho, 2009).

Marcado desde sua origem por fluxos e movimentos, ainda no período colonial, e em um contexto definido não somente pelos fluxos mercantis, mas também por profunda aridez e episódios de fome, Cabo Verde desenvolve uma dinâmica migratória de duplo caráter - espontânea e forçada. No caso da mi- 
gração espontânea, sua origem pode ser traçada nas conexões com a América do Norte surgidas durante o comércio de escravos e consolidadas no início do século XIX com navios baleeiros de New England que faziam paradas em Cabo Verde e contratavam homens jovens cabo-verdianos para o trabalho nos barcos. Diante das subsequentes crises locais, estes homens aproveitavam a oportunidade para emigrar para os Estados Unidos, abrindo uma rede migratória que, ainda hoje, é a preferencial em diversas ilhas do arquipélago (Carling, 2001; Meintel, 2002). No caso da emigração forçada, esta ocorre por volta dos anos de 1970, quando os colonizadores portugueses transportam centenas de cabo-verdianos para São Tomé e Príncipe para o trabalho nas roças de café e cacau (Carreira, 1982). Com o tempo, os percursos migratórios vão se diversificando prioritariamente para países da Europa, sobretudo para Portugal, mas também para a França, Itália, Holanda e outros países. A configuração desses percursos nos permite afirmar que a emigração é um fator estruturante nesta sociedade, atravessada historicamente por fluxos migratórios que deixam marcas profundas em sua estrutura social (ver Vasconcelos, 2012; Carling, 2002).

Como o leitor pode concluir, esta estrutura é também central no desenvolvimento das dinâmicas familiares que encontramos atualmente no arquipélago de Cabo Verde. Temos, portanto, uma sociedade crioula moldada por assimetrias e antagonismos originários certamente de sua formação escravocrata, mas também dos distintos percursos migratórios que garantiam ou não provisões para as famílias que ficavam nas ilhas. Em função da ausência relativa do homem-pai ao longo da história, vemos operar um modelo patriarcal, fundamentado na autoridade do pai, porém combinado com uma prática social baseada na díade mãe-filho. Configurando uma relação estável e contínua, a relação entre mãe e filho nasce primeiro no modelo escravocrata, sendo depois alimentada pelos percursos migratórios, sobretudo masculinos. ${ }^{4}$

A configuração familiar que se forma é, portanto, marcada por uma transitoriedade nas relações conjugais bem traduzida nos termos mãe-de-fidju ou pai-de-fidju, ou seja, mãe do meu filho ou pai do meu filho: aquele(a) com o(a) qual tenho um filho. Estas denominações, comumente utilizadas, indicam as ambivalências que sublinham as relações conjugais e a centralidade que assumem as relações de filiação. No final das contas, as relações entre este homem e esta mulher se dão por intermédio do filho que os une, e não na sua conjugalidade. Como veremos mais adiante, os termos marido e esposa são empregados, em geral, quando o casamento se formaliza perante a Igreja e/ou o Estado: "casamento no papel".

Conforme diversos autores apontam (Carreira, 1984; Fortes, 2013; Drotbohm, 2009; Lobo, 2014; Lobo; Miguel, 2015), é comum nas ilhas que o homem vivencie sua sexualidade e afetividade por meio de relações com mais de uma mulher. Tratar-se-ia, para alguns, de uma poligamia informal (Carreira, 1984; Fortes, 2013; Correia; Silva, 2014) na medida em que não há a formalização de um sistema poligâmico, mas este se efetiva no cotidiano das ilhas. Sua prática vem ocasionando uma transitoriedade entre parceiros e uma relativa instabilidade nos laços conjugais, especialmente na perspectiva das mulheres, que acabam por ter mais de um pai-de-fidju sem a garantia de que algum deles fique na casa e se responsabilize pelo acompanhamento dos filhos, inclusive financeiramente.

Um sistema familiar com tais atributos é frequentemente definido pelas ausências - de pai, de estabilidade, de equilíbrio e de poder econômico - e pelas noções de desestrutura, de disfuncionalidade. A ideia de que a família cabo-verdiana seria bem caracterizada pela desestrutura é partilhada em diversas esferas. Nos últimos anos, venho acompanhando no âmbito do governo o debate em torno da formulação do Plano Nacional de Acção para a Promoção e o Desenvolvimento da Família Cabo-Verdiana (2011-2015 (Governo de Cabo Verde, 2011). O documento parte de um diagnóstico de alto índice de vulnerabilidade social, com uma preponderância de famílias ditas monoparentais e chefiadas por mulheres, um baixo índice de casamento e um alto número de violência doméstica. Diante deste quadro de "disfuncionalidades das famílias" (p. 33), o Plano busca desenvolver orientação estratégica para todos os setores que intervêm na área, aglutinando e sistematizando as diferentes políticas sociais setoriais com implicações na família a fim de promover sua melhor estruturação (p. 12).

Mas desestrutura e disfuncionalidade também eram noções que meus interlocutores de pesquisa acessavam durante meu trabalho de campo. Com relativa frequência, quando questionada sobre o tema de minha pesquisa, explicava que meu interesse principal era entender a organização familiar em Cabo Verde, e a resposta era a seguinte: “então você está no lugar errado, porque aqui não tem organização familiar, mas desorganização!”. Após o choque inicial ao ouvir coisas assim, busquei explorar as vias pelas quais a ideia de desestrutura era construída. Arrisco dizer que, de certo modo, ela era resultante da comparação e do contraste entre formas familiares.

4. Como saliento em meu trabalho de 2014, sobre organização familiar e emigração feminina na llha da Boa Vista a partir dos anos 1960 , em alguns pontos do arquipélago (Ilha de São Nicolau, Ilha da Boa Vista e, em alguma medida, na llha de São Vicente e do Sal) observa-se o crescimento da emigração feminina. Na Illha da Boa Vista, a rede migratória feminina ultrapassa, em número, a emigração masculina; entretanto, este é um fenômeno localizado, tal como analiso no referido trabalho. 
Uma que se atualizava por meio da centralidade da mulher, do laço forte entre mãe e filho, da ausência relativa do marido-pai, da solidariedade feminina e da construção de laços familiares que enfrentavam as dinâmicas de proximidades e distâncias decorrentes do valor dado à mobilidade (inclusive a migratória). Outra, idealizada, que se realizaria na elite local e no mundo europeu, onde os homens seriam fiéis, as relações seriam monogâmicas, nucleares e estáveis e as responsabilidades, partilhadas de forma igualitária entre o casal.

Esta comparação entre modelos, que opera e é acionada no cotidiano das ilhas e verbalizada pelas mulheres em um tom de queixa - nos documentos governamentais, nos planos de desenvolvimento e nos acordos internacionais - adquire um tom normativo. Chega-se inclusive à culpabilização das formas familiares presentes no cenário da mobilidade pelas mazelas sociais e à ideia de que a família precisa ser corrigida. Certamente esta interpretação não é partilhada por todos os cientistas sociais que têm se debruçado sobre o entendimento das dinâmicas familiares não só em Cabo Verde, mas também em outros países. ${ }^{5}$ Em larga medida, estes partilham da visão de que modelos e práticas necessitam ser relativizados mediante o conhecimento de manifestações históricas e do reflexo das vivências afetivo-sexuais e dinâmicas familiares na formação das realidades sociais.

Se voltamos algumas páginas na história de Cabo Verde, compreendemos que modelos em disputa são inerentes ao processo de formação desta sociedade e, certamente, são retroalimentados contemporaneamente não só pelos migrantes, mas também pelos múltiplos contatos entre esse país e o restante do mundo. Portanto, creio ser acertada a interpretação de que, quando olhamos para as dinâmicas afetivo-sexuais e conjugais, vemos mulheres e homens enfrentando dilemas e desafios entre modelos. Mas a questão que me instiga aqui é a maneira como estes modelos se relacionam no âmbito das relações conjugais entre homens e mulheres. Ou seja, a partir dos dados que apresento a seguir, quero me distanciar de uma interpretação anterior segundo a qual estes modelos convivem em disputa, para construir uma análise que advoga pela complementaridade entre eles. Olhar para os ciclos de vida de mulheres e suas famílias será minha ferramenta para construir esta reflexão.

\section{Construindo conjugalidades em terrenos escorregadios}

E assim eu vim criando meus filhos, porque homem não, eles vão arranjando outras mulheres... e nós todas passávamos sacrifício para criar nossos filhos, trabalhava duro para criar os filhos porque pai-de-fidju não ajudava grandes coisas na criação de filhos, felizmente eu tinha meus pais que me ajudaram muito. [...] Quando eu tive meu primeiro filho, eu fiquei na "nossa casa" [casa dos pais]. Ele não tinha como me colocar em uma casa... Em princípio ele ainda não tinha aquelas outras. Primeiro ele veio arranjar essa, que é F. Meu terceiro filho e o primeiro dela têm uma diferença de dois meses. Depois que eu já tinha quatro, cinco filhos, ele veio arranjar aquela outra [risos]. Aquele primeiro filho deles dois e C. são colegas [da mesma idade]. Aí a gente veio ficar naquela luta, era um brigar, uma confusão sem fim. Isso porque elas eram "atrevidas", entraram no nosso meio e ainda vinham buscar confusão. Eu não tinha aquela qualidade de fazer guerra, eu não fui criada assim dentro de casa, porque nós fomos bem-criados [...]. Quando eu tive meu filho seis, é que papai morreu, aí eu saí de nossa casa para ir viver com ele. Nós moramos em três lugares, mas aí papai morreu e mamãe ficou aqui, já estava "grande" [idosa], e eu quem cuidava dela, deixava os filhos para trás e vinha cuidar dela, até que resolvi que, ou se pagava aluguel, ou se comia, e aí vim de novo para nossa casa com meus filhos. Quando ela morreu, a casa já estava velha, era de palha e, quando chovia, era um horror. Aí meus irmãos disseram: você faz um esforço e conserta a casa que nós te damos a nossa parte. Como somos unidos, eles me deram a parte deles porque eu cuidei dela e ela morreu nos meus braços, eles reconheceram isso. [...] Então eu e meus filhos moramos a vida toda aqui, ele vinha sempre, ficava um pouco aqui e ali... com esses homens dessa qualidade aqui na nossa terra, a vida é muito difícil. Eu tive a ajuda da minha família e trabalhei muito, então todos os meus filhos sabem que sua mãe trabalhou muito para eles, que ela deu todo o carinho que ela poderia dar, toda ajuda que pode e todo o sacrifício com seu pai. E hoje eles fazem tudo o que podem para mim. Eles são nove filhos, eu pari nove. Sete meninas e dois rapazes, todos eles ainda estão aqui comigo, pariram seus filhos, mas eu nunca botei nenhum na rua, vivemos todos aqui, filhos, netos e, depois que ele sossegou, ele também [...]. Eu tenho uma "reforma" [aposentadoria] que é uma bagatela, a reforma dele ainda é mais pouco do que a minha, e ele não vai mais para o mar, pois já está

5. No Brasil, Claudia Fonseca $(2004,2006)$ tem sido uma voz forte nesta linha analítica, em diálogo com autoras, sobretudo feministas, que reavivaram os estudos do parentesco a partir dos anos 1990 (Carsten, 2000; Strathern, 1989; Franklin; McKinnon, 2001; Weston, 1991). 
grande, tem problema de saúde e os filhos não querem mais que ele vá para o mar. Mas ele ainda bota rede e pega um peixinho. Agora ele está sossegado aqui. Faz uns anos que "casamos no papel", foi uma festa muito bonita na igreja que os filhos fizeram... homem é assim, com o tempo sossega, até porque, como diz aquela estória, ele já não pode mais [risos]. Agora nenhuma delas precisa mais dele e o deixaram para mim. Depois de tanta briga.... Hoje, eu e F., a gente se fala, mas com a outra não, ainda tenho muita mágoa com ela. (Entrevista com D. Fátima, 2005).

A minha primeira filha eu tive com um homem que me "queria para grandeza" e fazia tudo por mim, ele era mais velho. Foi só depois que eu vim descobrir que ele tinha uma mulher, foi na época que eu engravidei, mas perdi o bebê. Depois de um tempo, engravidei de K., essa vingou. Mas aí vieram os problemas, ele foi ficando estranho e violento e, quando a menina tinha dois anos, eu resolvi que não dava mais, ele ficou revoltado, foi muito problema. Mas aí depois arranjei com L., ele também já tinha uma filha, mas eu não tomei ele de ninguém, a mãe dela estava emigrada na Itália, então não tomei ele dela [risos]. Mas L. sempre foi mulherengo, várias mulheres já andaram com ele e eu tive que brigar com todas elas, sempre fiz questão de tomar meu homem de volta só para mostrar que é comigo que ele vai ficar. A maior confusão foi com a mãe de S., pois ela sempre foi atrevida e espalhafatosa, ela chegou a tirar ele de mim, foi por causa dela que nós ficamos separados durante sete anos. Eu estava grávida de C. quando tudo aconteceu, eu fui ter o bebê na Praia e ela estava com dois meses de grávida, foi tanta briga que ficamos separados por um tempo. Numa das brigas, eu disse a ela que estava perdendo uma batalha, mas não havia perdido a guerra, que ele ainda seria meu e para sempre. Enfim, foi o que aconteceu. Depois de muitos anos, estamos na nossa casa, moramos eu, nosso filho, o filho dele com ela e K. com seu filho, meu neto! Ele ainda não sossegou, eu tenho que ter paciência porque um dia ele vai cansar... é uma vida difícil com esses homens de Cabo Verde, mas eu sou doida por ele [risos]! O pior é ver K. [a filha] passando por tudo o que já passei... esses homens são nossa sina... (Entrevista com Maria, 2005).

Os trechos acima, das conversas com D. Fátima e Maria, ${ }^{6}$ sintetizam bem os percursos das relações entre homens e mulheres em diferentes fases da vida, e é a partir deles que pretendo detalhar para o leitor as possíveis trajetórias de relacionamentos conjugais vividas em um processo. Meu argumento é que as relações afetivo-conjugais são vividas de formas distintas no trajeto de vida de homens e mulheres, com reflexos para os ciclos de vida dos grupos domésticos. Nesse enfoque, ressalto as formas que a conjugalidade pode assumir ao longo da vida e as estratégias de construção de proximidades adotadas pelas mulheres no cotidiano de suas relações com os homens.

Observando elementos que compõem a trajetória de D. Fátima, percebemos que, em um primeiro momento, a relação entre ela e seu companheiro é marcada por filhos, pela não coabitação e pelo partilhar deste homem com outras duas mulheres. Por muitos anos, ela permanece na casa de sua família, apoiada pelos pais, sob a justificativa de que ele não tinha condições financeiras de "colocá-la" em uma nova casa. $\mathrm{Na}$ condição de primeira mulher entre as três, e já com alguns filhos, sua relação com ele transita para a coabitação. Primeiro passam a coabitar em uma nova casa e, após a morte de seus pais, D. Fátima e seus filhos vão para a casa da família, agora ela como proprietária de direito, sendo que o pai-de-filho "ia e vinha". Criaram-se os filhos, vieram os netos. Com o tempo, seu companheiro "sossega" e acabam por "casar-se no papel", no cartório e na igreja. O longo percurso deste casal, com nove filhos e mais de quinze netos à época da entrevista, é marcado por conflitos entre D. Fátima e as outras duas mães-de-filho de seu companheiro. Por fim, estas acabam por "deixá-lo para ela" em uma fase da vida dele que ela define pela ideia de "sossego".

Complementar ao caminho percorrido por D. Fátima, a trajetória de Maria revela também a disputa entre mulheres rivais e as estratégias utilizadas por ela para ficar com seu homem só para si. Se D. Fátima teve um parceiro para a vida, Maria tem filhos de distintos pais. Este não parece ser um fator de julgamento moral na trajetória feminina, desde que as relações afetivo-sexuais com diferentes homens não aconteçam ao mesmo tempo. Enquanto ao homem, é tolerado (o que é diferente de ser permitido) que tenha relações afetivo-sexuais com mais de uma mulher em um mesmo período de tempo, esta prática é vista como conduta inadequada para a mulher, sendo, portanto, fortemente repreendida pela sociedade. A história de Maria também revela que "ser a primeira" não é um dado, mas uma construção, e o fato de um casal ter filhos juntos não é garantia de que sua relação perdure. Quando conheceu L., ele já vivia com uma mulher há mais de quinze anos, uma relação também marcada por disputas entre ela e as "rivais". Após longo período vivendo em casas distintas, moravam agora em uma casa construída por ele.

Por diversas vezes, ela me disse que sua luta ainda não havia acabado, que ele ainda mantinha relação

6. Esses nomes são fictícios. Tal como acordado com minhas interlocutoras, seus nomes serão preservados para evitar sua exposição uma vez que os dados se tornem públicos. Trechos da entrevista também foram suprimidos para dificultar exposições das pessoas e das famílias. 
com suas outras mães-de-filho e mais uma ou outra que aparecesse. Nestas conversas, Maria se questionava sobre o porquê de manter uma relação que tanto a desgastava (já que não dependia dele financeiramente), e como resposta transbordava em seu relato um elemento pouco tratado na literatura antropológica sobre família e conjugalidade, o amor. Em meio a tentativas de encontrar uma resposta racional, ela afirmava que os homens são todos iguais, portanto ficava com ele mesmo. E acabava por concluir que era "doida por ele", que ele era o homem de sua vida e que teria paciência até ele sossegar.

Durante meu trabalho de campo, desenvolvi uma relação de amizade com D. Fátima e Maria, e suas casas sempre estiveram abertas para mim. Tive, portanto, a sorte de desfrutar de suas companhias e reflexões sobre seus relacionamentos, mas, sobretudo, pude acompanhar suas preocupações com as filhas, que, em suas histórias afetivas, acabavam por reproduzir um padrão muito próximo ao delas. D. Fátima salienta em seu relato que os filhos e netos vivem com ela. Maria também abriga em sua casa a filha e o netinho. Em alguma medida, refletindo sobre a reprodução, nas vidas de suas filhas, desta forma de se relacionar, elas expressam a "sina" da mulher cabo-verdiana: a espera.

Esta espera se conecta com uma concepção de que a masculinidade tem seus ciclos. Com muita frequência, o homem cabo-verdiano é caracterizado como um tipo conquistador, mulherengo, distante da família. Chega a ser banal a frase "o homem cabo-verdiano não serve", verbalizada por inúmeras mulheres na região investigada. E o fato de os homens desejarem ter mais de uma mulher é percebido como algo inerente à sua natureza. O desejo sexual masculino os tornaria predestinados a múltiplos relacionamentos.

Às mulheres, restaria o lamento e a vigilância, enquanto eles defendem o direito de ter uma vida $s a b$ (boa, agradável, alegre, gostosa). Ter uma vida sab é mais do que ter um prazer individual, é fazer parte de um estilo de vida altamente valorizado pelos homens. O estilo sab está ligado à noção de virilidade, um importante símbolo para a construção da masculinidade. Nos bares ou rodas de amigos, os homens falam de sua boa potência sexual, de suas conquistas e de como se saíram em situações conflituosas entre duas ou mais mulheres. O costume de se relacionar com mais de uma mulher gera comentários positivos e negativos, a depender de quem fala. Para o homem, é por meio dessa prática que ele ganha prestígio entre seus companheiros. Já as mulheres veem este costume com ambiguidade, pois, ao mesmo tempo que tal conduta masculina é fonte de conflitos, é também um evento esperado.

O fato é que, na região analisada, os conflitos entre rivais são assuntos preferidos nas rodas de conversa entre mulheres e homens. Tenho inúmeros relatos de brigas, flagrantes e casos de agressão entre rivais, inclusive de casos que chegaram à polícia. Os relatos variam no que concerne à natureza das relações: casos esporádicos, jogos de conquistas e dupla residência. As mulheres enviam recados e ameaças àquelas que invadem sua relação com o companheiro. Caso o aviso não resulte no fim dos boatos, elas podem chegar às vias de fato. As informações sobre o suposto caso circulam por intermédio das "faladeirezas" (fofocas), e a rivalidade ganha maiores proporções à medida que vai se tornando mais ampla a circulação desses rumores, o que lhes confere credibilidade. Em situações de suspeita, as parentes e amigas da mulher ameaçada partem para um processo de investigação que pode durar um longo período.

Todo o esforço da mulher que descobre ter uma rival se resume em afastá-la de seu companheiro, na tentativa de que a relação com essa concorrente não perdure e, principalmente, não gere filhos. Quando a mulher toma conhecimento de uma rival, sente um receio explícito de ser trocada por esta outra, e talvez por isso a preferência de que os casos sejam às escondidas, pois esse é um sinal de que o homem não pretende assumir a potencial concorrente. Quando o caso se torna público, a mulher é pressionada a tomar uma atitude, seja enfrentando a rival (fisicamente se for necessário) ou terminando a relação com o pai-de-filho.

Os filhos oriundos da relação são elos que podem fortalecê-la. Ao afirmar isso, não quero dizer que as mulheres se utilizam estrategicamente do nascimento de uma criança para assegurar o apoio do homem ou garantir que a relação entre eles perdure; creio que o que está em jogo é algo mais complexo do que isso. Como já salientei em outro trabalho (Lobo, 2012b), as crianças são um valor nos contextos familiares em Cabo Verde. Elas são desejadas, disputadas e assumem centralidade no cotidiano das casas. Além disso, ter filhos é um acontecimento essencial na construção de identidades femininas e masculinas, marcando a passagem para uma vida adulta. E, finalmente, além de criar e fortalecer laços entre homens e mulheres, filhos criam laços, também, entre famílias e entre casas, sendo atores importantes no processo de "fazer família" (Lobo, 2012b).

Como expresso nas entrevistas aqui apresentadas, a "primeiridade" de uma mulher é um fator favorável à estabilidade da relação, consistindo em dois fatores: já estar com um homem quando chegam outras mulheres e/ou ser sua primeira mãe-de-filho. Se relembrarmos as falas de D. Fátima e Maria, perceberemos uma insistência no argumento de que elas "já estavam" quando as outras chegaram. Quando um casal entra em conflito por causa da infidelidade do homem, algo que, aliás, é fonte constante de 
brigas entre as mulheres rivais, aquela que detém a primeiridade ameaça abandonar o companheiro. Isto, porém, dificilmente ocorre. O mais comum é, por um lado, o sentimento de que já foi investido muito tempo na relação e, por isso, ela tem o direito de querer conservá-la. Por outro, as mulheres têm uma sensação de impotência ou fraqueza, alegando que não conseguem se desvincular de um relacionamento que já dura um período considerável, especialmente se este relacionamento já tiver gerado filhos. Segundo elas, se deixarem o pai-de-filho, vão arranjar outro que lhes fará igual ou pior, por isso ficam onde estão e evitam ter filhos com mais de um pai. Outra razão levantada para explicar por que mantêm a relação com o pai-de-filho é o fato de que ele circula com outras, mas sempre volta. Creio que seja aí que reside todo o conflito entre uma mulher e suas rivais: no receio de ser abandonada pelo marido-pai, se ele optar por uma relação mais estável com outra mulher.

$\mathrm{O}$ valor da primeiridade para uma mulher se expressa nas vantagens que esta lhe oferece. $O$ fato de já estar com o homem antes da chegada de uma outra e de ser a primeira mãe-de-filho dá a ela um "direito" sobre o homem que se expressa concretamente no fato de ela poder brigar por ele. Porém, isso não garante a estabilidade da união, pois este pode, a qualquer momento, abandonar a mãe-de-filho e estabelecer uma relação fixa com outra mulher.

Um fator importante é a pressão familiar para que o homem escolha como mãe-de-filho permanente uma mulher que seja sua parente distante ou vizinha. É comum encontrarmos casais que sempre viveram como vizinhos, namoraram desde crianças e hoje mantêm uma relação estável. Nesses casos, não é só o fator tempo que entra como facilitador da estabilidade, mas também a proximidade das casas e das famílias, sendo que a mãe do companheiro tem grande influência para fazer de uma mulher a parceira preferencial dele, ou não.

Como espero ter demonstrado, os caminhos pelos quais os homens constroem sua masculinidade fazem com que as relações conjugais caminhem por terrenos escorregadios. A vivência de relações afetivo-sexuais com mais de uma parceira, o relativo distanciamento dos homens na relação conjugal (suas idas e vindas) e a ameaça constante de que esta relação se dilua são marcas das relações afetivas entre homens e mulheres jovens e parecem marcar tais relacionamentos desde seu início até que o homem atinja uma idade mais madura que as mulheres definem como período de sossego. Mas, antes de abordar esta etapa do ciclo de vida dos casais, gostaria de detalhar um pouco mais o processo de criação de elos entre eles.

\section{Filhos: laços frouxos ou elos sólidos?}

O caso de Dina e Lucas pode ajudar a melhor compreender alguns aspectos da afetividade na região investigada em seus primeiros momentos. Ambos jovens, com 15 e 17 anos, respectivamente, mantinham uma relação afetiva que ainda não tinha um caráter público. Dina me conta que não eram namorados, pois ele tinha sua "pequena". Encontravam-se de vez em quando e ela acabou por "pegar barriga". Lucas, de início, negou a paternidade, alegando que a moça não "andava" só com ele e que não iria assumir filho de outro. $\mathrm{O}$ fato gerou uma crise que ocasionou a ruptura das relações entre as famílias envolvidas. As discussões se prolongaram até o nascimento do filho, que veio ao mundo "com a cara do pai". A este só restou assumir a paternidade e registrar a criança, ou seja, dar-lhe seu sobrenome paterno. A tia de Dina contou-me que teve vontade de não permitir o registro, mas uma criança não pode ficar sem o sobrenome de um pai, "por pior que ele seja". Em compensação, o nome próprio dado à criança foi o do bisavô de Dina, um homem definido como correto, de respeito e que nunca havia injuriado nenhuma de suas mãesde-filho, segundo me contou a tia da moça.

A história dos dois jovens permite-nos uma compreensão geral da vida sexual na população estudada. Para rapazes e moças, ela começa, geralmente, antes dos quinze anos. Se, por um lado, uma perspectiva mais moralizante sobre a virgindade nunca foi tema de minhas conversas com mulheres mais velhas ou mais jovens, por outro lado, não consegui escapar ao tema da gravidez de moças jovens. E, em torno deste assunto, pude perceber eventos relativamente dramáticos. Apesar de sua relativa frequência, a notícia de moças grávidas era fonte certa de conflito familiar, ainda que este pudesse se dissipar com o passar dos meses e ser resolvido com o nascimento da criança.

As primeiras reações à gravidez de uma moça são diversas: tanto ela pode ser encarada como um fato comum, quanto pode gerar atitudes de reprovação. Esta segunda possibilidade faz com que a moça esconda o fato dos parentes, ou se submeta a um aborto, ou saia de casa. Às vezes, descoberta a gravidez, a moça é expulsa. Em todos os casos, ela busca refúgio nas parentes ou vizinhas, a quem pede socorro, e, por intermédio delas, restabelece as relações com a mãe num segundo momento. Esse é um processo ritualizado no caso da primeira gravidez de uma jovem: a tentativa de esconder o fato, seguida de um rompimento com a família, a mediação de parentes e amigas e o restabelecimento da relação familiar.

Em seguida, inicia-se a fase de reconhecimento da futura criança pelo suposto pai. Esse é um assunto 
para a avó materna da criança, pois a reação do homem varia nessas circunstâncias, e, quando a paternidade é negada, é a avó quem assume a responsabilidade sobre o neto, e pode até mandar a filha para a casa de um parente que vive longe a fim de evitar que o casal continue se encontrando. O reconhecimento legal da criança pelo pai é muito valorizado na Boa Vista. Se o homem duvida da fidelidade da mulher, ele se recusa a assumir a criança até que ela nasça, momento em que pode verificar, pela sua aparência, se ele é realmente o pai. Nesse momento, entra em cena a provável avó paterna da criança, cabendo a ela conferir se esta pertence à sua família.

Para reconhecer um filho, o pai deverá dar a ele seu sobrenome, o que cria laços entre os envolvidos diretamente na situação (pai, mãe e criança) e entre as famílias de um lado e de outro. Pina Cabral (2006), em um estudo preliminar sobre nominação na Bahia, reflete que os sobrenomes são nomes de grupos, e suas implicações para a pessoa que os recebe têm muito a ver com a natureza do grupo. Já o primeiro nome (ou nome próprio) geralmente tem um valor semântico, ou seja, transporta significados acerca da natureza individual da pessoa que o usa, podendo ser questionado ou até ser considerado de caráter negativo.

$\mathrm{O}$ autor lembra ainda que dar o primeiro nome pode representar uma tentativa de manipular a identidade do outro por meio dos significados que se atribuem ao nome dado - por exemplo, tal nome significa força, outro significa doçura. Dar o primeiro nome é, ainda, uma possibilidade de homenagear alguém. ${ }^{7}$

Interessado na maneira como, através dos nomes próprios, se formam associações entre pessoas, o autor argumenta que, pelos nomes, se constitui família. O ato de fazer família pela nominação de uma criança nos fornece um caminho para entender o processo de reconhecimento de paternidade na sociedade cabo-verdiana. O primeiro passo para reconhecer um filho é registrá-lo formalmente, o que tem um sentido importante para a mãe-de-filho e sua família, pois garante, em certa medida, o prestígio da moça perante a sociedade. Afinal, o registro confirma que o homem a quem ela atribuía a paternidade era, de fato, o pai, retirando a dúvida sobre sua fidelidade. Conheci inúmeras histórias que versavam sobre a paternidade, especialmente, em tom de piada, enfatizando que uma dita mulher afirmava que o pai era $\mathrm{A}$, e a criança nascia com a cara de B. Ao contrário do que se pode pensar, o grande alvo de tais piadas não é a mulher (apesar de sua má reputação decorrente de tal evento), mas o homem que acreditara ser o pai da criança.

Quando engravida, a mulher dá a criança a um homem, afirmando ser ele o pai. A depender da situa- ção do casal, o homem irá “tomá-la” ou questionar a veracidade da afirmação da mulher. Nesta última hipótese, haverá um processo de negociação entre os envolvidos, processo geralmente conflituoso e que deve terminar somente com o nascimento do bebê e a confirmação da paternidade por meio da categoria "parecer com". Sendo a paternidade confirmada pela matriarca da família do rapaz, este reconhece a criança registrando-a em cartório, ou seja, dando-lhe seu sobrenome.

É aí que entramos no segundo passo importante do reconhecimento da paternidade: o sobrenome propriamente dito, que é muito mais do que o registro. Para o pai e sua família, reconhecer um filho é dar-lhe o sobrenome paterno. Por exemplo, um filho de alguém que se chama Antônio de Souza Santos herdará o sobrenome paterno Santos, caso seja reconhecido. Isso significa que pertence aos Santos e será identificado formalmente como tal, independente das relações de proximidade que operem entre estes e a família da mãe. Tal fato se torna mais importante à medida que subimos nos estratos sociais e chegamos às famílias que constituem a elite local. Primeiro porque, ao receber o sobrenome do pai, a criança passa a pertencer ao grupo dele e, consequentemente, a ter alguns direitos nesse grupo. Em segundo lugar, porque isso significa uma forte possibilidade de estreitamento das relações entre as mulheres das famílias paterna e materna da criança, especialmente entre as duas avós.

Para a família da mãe, o reconhecimento significa que esta criança "tem um pai”. E ter um pai, sobretudo, um pai que assume a criança, é um privilégio tanto para ela quanto para sua mãe - isso não apenas no caso baiano, estudado por Pina Cabral (2006), mas também no caso da Boa Vista, um contexto em que as unidades sociais primeiras são as relações uterinas; o casamento formal é apenas uma possibilidade entre tantas outras. O privilégio da paternidade reconhecida não é necessariamente um privilégio material, visto que não garante apoio econômico, ajuda na educação ou mesmo a proximidade entre pai e filho. Trata-se de um privilégio simbólico, pois, no modelo de família considerado ideal, ter o nome do pai é marca de qualidade.

Quanto ao primeiro nome, geralmente, é dado pela mãe, que ao escolhê-lo, tem a possibilidade de homenagear alguém, podendo ser o pai da criança, ou algum parente da própria família ou da família dele. O nome dado pela mãe é, portanto, um meio de criar vínculos com a família paterna da criança ou de reforçar os próprios laços consanguíneos. Isso vai depender da qualidade das relações conjugais entre

7. Homenagem é, no caso estudado por Pina Cabral (2006), uma categoria nativa. O ato de homenagear alguém através do nome não se restringe à atribuição de seu primeiro nome a um descendente, podendo tomar outras formas, como a formação de um nome pela combinação de sílabas dos nomes dos parentes homenageados, entre outras. 
mãe e pai. Se o pai "merece" que a criança receba seu nome, esta é uma boa chance de homenageá-lo. Certamente, porém, não podemos vincular a homonímia somente ao fator merecimento, mas também a uma estratégia para criar vínculo entre pai e filho, a qual pode ser utilizada pela mãe numa tentativa de aproximar o homem de seu universo.

Nos casos mais conflituosos, como o de Dina e Lucas, a homenagem costuma ser transferida para algum homem da família materna, geralmente o avô, um tio ou outro parente que tenha dado apoio à mulher na gravidez ou em alguma outra fase de sua vida. Seja pelo nome próprio ou pelo sobrenome, o processo de reconhecimento de paternidade é uma forma de se "fazer família". 8 A situação de Dina não é excepcional: ouvi e acompanhei de perto muitas histórias como a sua. No entanto, vi que o desfecho nem sempre se repete, ou seja, não é recorrente que o pai assuma de imediato a paternidade de modo formal, dando seu sobrenome à criança. Além disso, mesmo nos casos em que tal acontece, isto não garante a proximidade entre as duas famílias, apesar de criar possibilidades para que ela ocorra. As candidatas mais prováveis para tomar conta da criança e assumir a responsabilidade de fato pelos seus cuidados e sustento são as avós materna ou paterna (Lobo, 2010). O que desejo enfatizar ao abordar a fase inicial da relação entre jovens é a maneira como as relações conjugais se conectam com os processos de filiação. É o filho que gera a possibilidade de que encontros fortuitos se transformem em relações que perduram no tempo, seja na esfera individual ou na das famílias envolvidas. O leitor pode corretamente pensar que esta afirmação tem uma validade mais geral, o que, de certa forma, é verdade. Mas o que me parece rico analiticamente não é a afirmativa em si, e sim observar toda a rede que se tece a partir de uma criança e como esse fato "faz família" neste contexto. 9 Se a afirmação tem uma validade universal, os contextos a preenchem de conteúdos específicos, e estes fazem diferença na antropologia.

\section{"Casamento no papel": um tempo de sossego}

No contexto investigado, quando um casal de jovens tem um filho, raramente o homem e a mulher vão juntos para uma casa em separado. Normalmente a mãe, junto com a criança, continua a viver com sua mãe ou com outra família na qual tenha sido criada, e o pai, do mesmo modo, permanece em sua casa. As relações de filiação, nesse caso, têm supremacia sobre a conjugalidade.

Nos casos em que os casais se encontram numa idade mais madura, o caráter transitório das relações tende a ser menos frequente. Eles vivem uma relação conjugal de fato, nem sempre formalizada pelo casamento, mas permanecem juntos, ou, ainda que em casas separadas, visitam-se diariamente. Normalmente a mulher vai dormir com o pai-de-filho ou companheiro, mas passa o dia no que chama de "nossa casa", onde afirma morar com os familiares imediatos.

Quanto maior a idade de um homem, mais comum é o seu discurso de busca pela tranquilidade e estabilidade conjugal. Os homens afirmam querer uma vida tranquila ao lado de sua mãe-de-filho. Apesar disso, é raro encontrarmos casais adultos que vivam numa situação formalizada pelo casamento legal. A forma mais comum de afetividade é a união de fato; o casamento legal é mais exceção do que regra.

A postergação do casamento formal geralmente está ligada à percepção de que é uma cerimônia cara e pouco importante. Porém, na prática, ele é vislumbrado enquanto possibilidade ou projeto, especialmente para as mulheres. Elas esperam casar, e a concretização do desejo depende mais dos homens do que delas. Direta ou indiretamente, o poder de decisão é masculino. Durante a pesquisa, era frequente ouvir as mulheres dizerem estar aguardando o homem se acalmar para formalizarem a união, pois casamento é coisa séria e para a vida toda. Essa hora chega para o homem quando sua idade já se encontra avançada, isto é, quando seus filhos estão criados e seus netos já circulam pela casa dos avós.

De acordo com o censo realizado na Ilha da Boa Vista no ano 2000, de 328 mulheres chefes de família recenseadas, 163 se diziam solteiras, 142 em regime de união de fato e apenas 23 se declararam casadas. Este dado está em conformidade com minha experiência de campo, na qual pude entrevistar e observar dezenas de mulheres e homens e conversar com eles sobre esse tópico. Verifiquei, portanto, que, na voz geral, o casamento é um passo sério, que exige responsabilidade e é para sempre.

O casamento formal é um importante símbolo de prestígio e, ainda mais, quando a cerimônia é realizada na igreja. Vemos, então, o modelo cristão, tão valorizado nesta sociedade enquanto referência de forma de vida ideal, sendo legitimado mediante a formalização de uma relação conjugal que já perdura por anos em situação de informalidade. Aliás, a raridade estatística dos casamentos formais não significa

8. Há ainda outras possibilidades de se fazer relação familiar pela nominação: os apelidos ou "nominhas" e os tecnonímios - fulano da casa de fulana ou cicrano da casa de beltrana).

9. É preciso lembrar, ainda, nesse contexto, a importância de ter um filho homem, tanto para o pai quanto para a mãe que aguarda a criança. 
um distanciamento do modelo cristão que os defende. Pelo contrário, indica uma adesão plena a ele. As pessoas se casam formalmente só quando se sentem em condições de seguir à risca o modelo, mantendo o casamento para sempre. Tais dados sugerem que, em sua opinião, vale mais a pena não se casar do que fazê-lo para depois romper tão importante laço.

O homem casa quando está disposto a assumir a responsabilidade com a família, mesmo que já o venha fazendo de fato. Com o casamento formal, que implica coabitação, a mulher se sente segura. Essa é a fase em que o homem já está sossegado e mais presente no universo doméstico. Geralmente, é nesse período que ocorrem os casamentos religiosos, cerimônias organizadas pelos filhos e netos do casal e que tendem a comemorar seus longos anos de união. Foi assim com um casal de amigos que fiz na Boa Vista, D. Raimunda e seu Justino. Quando completaram 25 anos vivendo juntos, os filhos organizaram sua cerimônia de casamento na igreja para comemorar e oficializar a união. Ela me confidenciou que sempre quis casar, pois é religiosa, porém nunca tiveram condições econômicas para tal. Além disso, seu Justino bebia muito e era homem de "sua paródia" (de festa). Agora ele já havia cansado daquela "má vida" de andar só com os companheiros e estava mais sossegado, por isso resolveu casar e fazer a festa que os filhos queriam.

Assim como para D. Fátima, o tempo do sossego também chegara para D. Raimunda, um tempo almejado por muitas mulheres que conheci. Um tempo que fecha um ciclo de vida conjugal vivida entre angústias e esperas, mas também marcado pelo fortalecimento de laços entre as famílias envolvidas e pela construção de suas vidas familiares por intermédio dos filhos que nascem desta relação. Em um universo de afetividade e de batalhas cotidianas dessas mulheres para conquistar os companheiros que escolheram "para chamar de seus", o tempo do sossego vem coroar uma vida de luta e espera.

\section{Da instabilidade ao processo}

Os casos aqui apresentados não se restringem à Ilha da Boa Vista, Cabo Verde, mas se aproximam de tantos outros contextos etnográficos. Lembro-me, por exemplo, de Edith Clarke em seu estudo sobre a Jamaica (1979). Diante de dados que em muito se assemelham aos aqui analisados, ela afirma que a instabilidade é a característica central das relações conjugais nas sociedades crioulas, notando que nestes contextos sociais são institucionalizadas relações extrarresidenciais, não domiciliares ou de visitação, e com várias alternativas de padrão conjugal. Outro aspecto essencial dessas relações, segundo Clarke, diz respeito à idade ideal para o casamento: este deve acontecer em idade elevada, sendo típica a oficialização precedida por vários anos de coabitação. É normal que pai e mãe se casem depois dos filhos já crescidos e até mesmo depois de já serem avós. A autora ressalta ainda que são poucos os homens que têm somente uma união conjugal na Jamaica. Em sua maioria, mantêm duas ou mais uniões, além de se envolverem numa série de encontros fortuitos.

Apesar de dados de pesquisa tão próximos, creio que nossos caminhos analíticos para lidar com as fases pelas quais passam os relacionamentos conjugais muito se distanciam. No meu caso, acho fundamental que, no lugar de aceitar, como Edith Clarke, a ideia de instabilidade, nos questionemos se o casamento adiado não significaria uma estratégia dentro de outra escala de prioridade. Será que, para estas mulheres, ele não teria um caráter processual?

Para esclarecer tal ponto, proponho que nos voltemos para a etnologia africana clássica da escola estrutural funcionalista, uma vez que os autores dessa vertente também se ancoram em dados etnográficos que em muito se aproximam do que percebi em Cabo Verde. Fortes (1969), em sua análise sobre o casamento tallensi, afirma que as uniões são instáveis nos estágios iniciais. Um jovem raramente fica permanentemente com sua primeira noiva, e as moças veem seu primeiro casamento como um experimento, exceto nos casos em que o marido é mais velho ou o casamento é fruto de uma negociação. Homens maduros dizem não se lembrar de todas as mulheres que tiveram. No entanto, apesar de o casamento não representar um laço definitivo para os Tallensi, muitos casais ficam juntos para a vida toda. Em seu esforço por entender o casamento africano, Radcliffe-Brown (1952) afirma que não devemos pensá-lo como um evento ou uma condição, mas como um processo em desenvolvimento.

Diante destes exemplos, arrisco dizer que as relações conjugais que aqui descrevo podem ser menos instáveis do que parecem em um primeiro momento. A instabilidade como fator negativo surge quando colocamos essas práticas locais em comparação com um modelo considerado ideal, que funde filiação, conjugalidade e residência para a constituição da família. Em face desse modelo, que valoriza a perspectiva ocidental-cristã, o universo local aparece como disfunção. Em minha análise, percebo que, tal como outras formas tradicionais africanas, o casamento na região estudada é progressivo, resultado de um processo de negociações longo e que se desenvolve em fases. Diferentemente do que conclui Edith Clarke, minha opção não é pela ideia de instabilidade, mas pela noção de processo.

Ao me debruçar sobre as vidas e as histórias familiares de mulheres como D. Fátima, Maria, D. Rai- 
munda e suas filhas e netas, percebo que o casamento e outras formas de união não podem ser vistos como formas alternativas de associação conjugal em que o indivíduo é livre para escolher. Enquanto a união de fato é um tipo de arranjo que não envolve um laço conjugal seguro ou uma relação bem-definida de parentesco, o casamento legal é visto como um passo sério e que exige responsabilidade de ambas as partes. Este ocorre, então, como o último estágio de uma associação que antes tomou outras formas: primeiro vêm os encontros mais ou menos fortuitos (com ou sem filhos), depois, as uniões de fato e, por fim, o casamento. Ele é uma indicação de que foram preenchidas as condições econômicas e sociais para tal. A oficialização é o sinal de que as partes contratantes se aprovaram a ponto de se submeterem ao risco da mudança de status e à responsabilidade que o casamento implica. Esse tipo de união marca o fim de uma livre associação que pode, teoricamente, ser dissolvida a qualquer momento. $\mathrm{Na}$ concepção das mulheres da região, só se deve casar depois que o homem para de andar por aí, "sossega e senta a cabeça em casa".

No meu entender, o que marca a vida delas não é o dilema das formas de conjugalidade, uma que se realiza e outra que é um devir, mas a construção, em processo, das bases sólidas para o "tempo do casamento". Minha ênfase analítica nos processos de transformação de formas de conjugalidade e afetividade se constrói numa busca por me distanciar de análises que esperam que a ausência de traços comumente associados ao universo familiar deva resultar em uma tensão vinculada a problemas de identidade e de afeto. Estudos antropológicos vêm construindo imagens que salientam a complexidade das atitudes, experiências e expectativas dos contextos de filiações, conjugalidades e afetos e demonstrando que este não é o caso. Tais contextos são arenas de disputas, conflitos, tensões e poder, mas também de afetos, sentimentos e escolhas. Abordá-los por uma perspectiva nuançada de suas práticas permite que nos afastemos do risco de analisá-los como modelos alternativos, visão que pressupõe a concordância com a existência de um modelo familiar "normal" ou hegemônico, do qual os demais se distanciam.

\section{Referências}

BARROS, Crisanto. A ascensão dos pobres a posicões de elite político-administrativa no contexto do Cabo Verde pós-independente. Ciencias Sociais Unisinos, São Leopoldo, RS, v. 49, n. 1, p. 54-63, 2013.

CARLING, Jorgen. Aspiration and ability in international migration: Cape Verdean experiences of mobility and immobility. Oslo: Ed. University of Oslo, 2001.
CARLING, Jorgen. Migration in the age of involuntary immobility: Theoretical reflections on the Cape Verdean experience. Journal of Ethnic and Migration Studies, London, v. 28, n. 1, p. 5-42, 2002.

CARREIRA, Antonio. The people of the Cape Verde Islands: Exploitation and emigration. Hamden, CT: Archon, 1982.

CARREIRA, Antonio. Cabo Verde: aspectos sociais: secas e fomes do século XX. Lisboa: Ulmeiro, 1984.

CARSTEN, Janet. Cultures of relatedness: New approaches on the Study of Kinship. University of Edinburgh: Edinburgh, 2000.

CLARKE, Edith. My mother who fathered me: A study of the family in three selected communities in Jamaica. London: G. Allen \& Unwin, 1979.

CORREIA E SILVA, Antonio. Dilemas de poder na história de Cabo Verde. Lisboa: Rosa de Porcelana, 2014.

DEFRAYNE, Elisabeth. Au rythme des tambor: ethnographie des mobilités des "gens de Santo Antão" (Cap-Vert, Belgique, Luxembourg). 2016. Thèse (Doctorat en Sciences Politiques et Sociales: Anthropologie) Université Catholique de Louvain, 2016.

DROTBOHM, Heike. Horizons of long-distance intimacies reciprocity, contribution and disjuncture in Cape Verde. History of the Family, v.14, p. 132-149, 2009.

FONSECA, Claudia. Família, fofoca e honra: etnografia de relações de gênero e violência em grupos populares. Porto Alegre: Editora UFRGS, 2004.

FONSECA, Claudia. Os caminhos da adoção. São Paulo: Cortez, 2006.

FORTES, Celeste. "M t'studa p'm k ter vida k nha mãe tem”: género e educação em Cabo Verde. Ciencias Sociais Unisinos, São Leopoldo, RS, v. 49, n. 1, p. 80-89, 2013.

FORTES, Celeste. "Casa sem homem é um navio à deriva": Cabo Verde, a monoparentalidade e o sonho de uma família nuclear e patriarcal. Anuário Antropológico, Brasília, v. 40, n. 2, p. 151-172, 2015.

FORTES, Meyer. Web of kinship among the Tallensi: The second part of an analysis of the social structure of a transvolta tribe. London: Oxford University Press, 1969.

FORTES, Meyer. O ciclo de desenvolvimento do grupo doméstico. Brasília: Ed. UnB, 1974.

FRANKLIN, Sarah; McKINNON, Susan (Ed.). Relative values: reconfiguring Kinship Studies. Durham; London: Duke University Press, 2001.

GOVERNO DE CABO VERDE. Plano Nacional de Acção para a Promoção e o Desenvolvimento da Família Cabo-Verdiana (2011-2015). Praia, 2011.

LAURENT, Pierre-Joseph. Famílias sob influência de leis migratórias dos países de acolhida: comparação das migrações cabo-verdianas nos Estados Unidos e na Itália. In: DIAS, Juliana Braz; LOBO, Andréa (Org.). Mundos em circulação: perspectivas sobre Cabo Verde. Brasília; Praia: ABA Publicações: EDUni-CV: Letras Livres, 2016. p. 137-197.

LOBO, Andréa. Tão longe e tão perto: organização familiar e emigração feminina na Ilha de Boa Vista-Cabo 
Verde. 2006. 272 f. Tese (Doutorado em Antropologia Social). Universidade de Brasília, Brasília, 2006.

LOBO, Andréa. Um filho para duas mães? Notas sobre a maternidade em Cabo Verde. Revista de Antropologia, São Paulo, v. 53, p. 117-146, 2010.

LOBO, Andréa. A família em Cabo Verde: uma perspectiva antropológica. Revista de Estudos Cabo-Verdianos, Praia, v. 4, p. 99-114, 2012a.

LOBO, Andréa. Vidas em movimento: sobre mobilidade infantil e emigração em Cabo Verde. In: DIAS, Juliana Braz; LOBO, Andréa (Org.). África em movimento. Brasília: ABA Publicações, 2012b. p. 65-83.

LOBO, Andréa. Tão longe e tão perto: famílias e "movimentos" na Ilha da Boa Vista de Cabo Verde. Revised ed. E-Book. Brasília: ABA Publicações, 2014.

LOBO, Andréa; MIGUEL, Francisco. "I want to marry in Cabo Verde": Reflections on homosexual conjugality in contexts. Vibrant, Brasília, n. 12, p. 37-66, 2015.

MEINTEL, Deirdre. CapeVerdean transnationality, old and new. Anthropologica, Lima, Peru, v. 44, n. 1, p. 25-42, 2002.

MILLER, Daniel.What is a relationship? Is kinship negotiated experience? Ethnos, São Paulo, v. 72, n. 4, p. 535-554, 2007.

PINA CABRAL, João. Em nome do pai: mães e nomes no Baixo Sul (Bahia, Brasil). Lisboa: Instituto de Ciências Sociais da Universidade de Lisboa, 2006. Trabalho apresentado no Simpósio Internacional Nomes e Pessoas: Gênero, Classe e Etnicidade na Complexidade Identitária. RADCLIFFE-BROWN, Alfred Reginald. Introduction. In: RADCLIFFE-BROWN, Alfred Reginald; FORDE, Daryll (Ed.). African systems of kinship and marriage. London: Oxford University Press, 1952. p. 79-132.

SCHNEIDER, David. A critique of the study of kinship. Ann Arbor: University of Michigan Press, 1984.

STRATHERN, Marilyn. After nature: English kinship in the twentieth century. Cambridge: Cambridge University Press, 1989.

TRAJANO FILHO, Wilson. The Conservative aspects of a centripetal diaspora: The case of the Cape Verdean tabancas. Africa(s), v. 79, n. 4, p. 520-542, 2009.

WESTON, Kath. Families we choose: Lesbians, gays, kinship. New York: Columbia University Press, 1991.

VASCONCELOS, João. "Manera, ess muv?”: a mobilidade como valor em São Vicente de Cabo Verde. In: DIAS, Juliana Braz; LOBO, Andréa (Org.). África em movimento. Brasília: ABA Publicações, 2012. p. 49-64. 


\title{
About strong women and absent men: thinking conjugalities as processes in Cape Verde
}

\begin{abstract}
The article addresses the themes of affectivities, possible forms of conjugalities and the dilemmas faced by men, but especially by women, in the process of building marital relationships. Based on research data in the archipelago of Cape Verde, in which family relations would be marked by a feminine centrality combined with a patriarchal system in which the fundamental affective bond would be that between mother and child and the relations of affiliation would have preponderance over those based on affinity; I argue that the affective-conjugal relations are lived in different ways in the life paths of men and women with reflexes for the life cycles of the domestic groups, giving attention to the forms that the conjugality can assume throughout the life and the strategies of construction of proximities adopted by women in the daily life of their relations with men.
\end{abstract}

Keywords: conjugalities, affectivity, life cycles, Cape Verde, families.

\section{Sobre mujeres fuertes y hombres ausentes: conyugalidades como procesos en Cabo Verde}

\section{Resumen}

El artículo aborda las afectividades, las formas posibles de conyugalidades y los dilemas enfrentados por hombres y mujeres, pero sobre todo por mujeres, en el proceso de construcción de las relaciones conyugales. Los datos de investigación tienen como locus el archipiélago de Cabo Verde. En Cabo Verde, las relaciones familiares serían marcadas por una centralidad femenina combinada con un sistema patriarcal. El lazo afectivo en ese contexto sería aquel que es establecido entre madre e hijo(a) y las relaciones de filiación tendrían preponderancia sobre aquellas basadas en la afinidad. Argumento en esta investigación que las relaciones afectivo-conyugales son vividas de formas distintas en las trayectorias de vida de hombres y mujeres y tienen reflejos sobre los ciclos de vida de los grupos domésticos. Destaco además las formas que la conyugalidad puede asumir a lo largo de la vida y las estrategias de construcción de proximidades adoptadas por las mujeres en el cotidiano de sus relaciones con los hombres.

Palabras clave: conyugalidades, afectividades, ciclos de vida, Cabo Verde, familias.

Data de recebimento do artigo: 02/11/2016

Data de aprovação do artigo: 01/04/2017 
